\title{
ChemComm
}

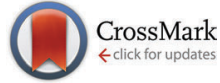

Cite this: Chem. Commun., 2016, 52, 9279

Received 2nd May 2016,

Accepted 24th June 2016

DOI: $10.1039 / c 6 c c 03649 j$

www.rsc.org/chemcomm

\section{Tin-based composite anodes for potassium-ion batteries $\dagger$}

\author{
Irin Sultana, Thrinathreddy Ramireddy, Md Mokhlesur Rahman, Ying Chen and \\ Alexey M. Glushenkov*
}

The electrochemical behaviour of a Sn-based anode in a potassium cell is reported for the first time. The material is active at low potentials vs. $\mathrm{K} / \mathrm{K}^{+}$, and encouraging capacities of around $150 \mathrm{~mA} \mathrm{~h} \mathrm{~g} \mathrm{~g}^{-1}$ are recorded. Experimental evidence shows that $\mathrm{Sn}$ is capable of alloying/ de-alloying with potassium in a reversible manner.

Renewable energy sources (e.g., wind, solar, biomass, tidal and geothermal) should be supplemented by sustainable storage technologies in order to meet the growing energy demand of the modern society and the intermittent nature of energy supply. ${ }^{1}$ Among the potential energy storage technologies, lithium-ion (Li-ion) battery technology is the most suitable one at present; however, the large-scale application of lithiumion batteries may face price constraints and resource limitations. ${ }^{2,3}$ Recently, sodium-ion (Na-ion) and potassium-ion (K-ion) batteries (which share the same "rocking chair" principle of operation as their Li-ion counterparts) have received renewed attention because of the abundance and low cost of these elements. ${ }^{4,5}$ Indeed, potassium and sodium elements occupy 2.09 and $2.36 \mathrm{wt} \%$, respectively, of the Earth's crust in contrast to $\mathrm{Li}$, which contributes only $0.0017 \mathrm{wt} \%{ }^{6}$ While sodium-ion battery chemistry has been the focus of numerous studies in the last few years, potassium-ion batteries are less studied and are in the earlier stage of development. According to Komaba et al.,$^{5}$ this type of batteries may be potentially capable of being high voltage systems $(4 \mathrm{~V}$ class batteries).

Materials that have been studied for electrodes of K-ion batteries are rather limited at present. On the cathode side, Prussian blue/Prussian blue analogues, ${ }^{7,8} \mathrm{FeSO}_{4} \mathrm{~F},{ }^{9}$ and amorphous $\mathrm{FePO}_{4}{ }^{10}$ have been investigated. On the anode side, graphite, ${ }^{5,11,12}$ hard and soft carbon ${ }^{11,13}$ as well as reduced graphene oxide ${ }^{12}$ have been evaluated. The most interesting effect here is that

Institute for Frontier Materials, Deakin University, 75 Pigdons Rd, Waurn Ponds, Geelong, VIC 3216, Australia. E-mail: alexey.glushenkov@deakin.edu.au;

Fax: +613 52271103; Tel: +613 52272931

$\dagger$ Electronic supplementary information (ESI) available: Experimental details, additional TEM images, and EDS, TGA, and electrochemical data. See DOI: $10.1039 / \mathrm{c} 6 \mathrm{cc} 03649 \mathrm{j}$ graphite is capable of intercalating potassium ions, delivering a high capacity of up to $\sim 273 \mathrm{~mA} \mathrm{~h} \mathrm{g^{-111 }}$ and displaying low potential plateaus, while the amount of sodium that can be intercalated is quite small (the compositions of $\mathrm{NaC}_{70}{ }^{14}$ and $\mathrm{NaC}_{64}{ }^{15}$ in sodium cells have been measured upon sodium intercalation in graphite). An interesting class of high capacity anode materials that may be used in lithium and sodium cells includes the materials (e.g., $\mathrm{Si}, \mathrm{Sb}, \mathrm{Sn}$, etc.) that can electrochemically alloy with these elements. ${ }^{16,17}$ However, this class of materials has not been explored for K-ion batteries yet, with the only exception of Sb-based electrodes, demonstrated as possible anodes in potassium-ion/oxygen batteries. ${ }^{18}$ There is a scope to investigate other materials that can alloy with potassium.

Here, we attempt to investigate anodes based on tin (Sn) as possible electrode candidates for K-ion batteries. Sn is a known anode for Li-ion and Na-ion batteries, capable of producing $\mathrm{Li}_{4.4} \mathrm{Sn}$ and $\mathrm{Na}_{15} \mathrm{Sn}_{4}$ alloys reversibly in these cells and possessing theoretical capacities of 991 and $845 \mathrm{~mA} \mathrm{~h} \mathrm{~g}^{-1}$ with lithium and sodium, respectively. ${ }^{16,17}$ The electrochemical performance of pure Sn is, however, unsatisfactory, due to the mechanical degradation of the electrodes caused by large volume changes during the cycling process. ${ }^{19,20}$ A common way to overcome this issue is to prepare Sn-based electrodes in the form of a Sn-carbon composite in which Sn nanoparticles are mixed with or dispersed in a carbon component. ${ }^{21}$ In order to evaluate $\mathrm{Sn}$ as a possible candidate for an electrode material for K-ion batteries, we have also prepared the material in the form of a Sn-carbon composite. Experimental evidence suggests that $\mathrm{Sn}$ is capable of alloying/ dealloying with potassium in a reversible manner.

A Sn-carbon (Sn-C) composite was prepared via mechanical ball-milling (for further experimental details see the ESI $\dagger$ ). $70 \mathrm{wt} \%$ of Sn powder and $30 \mathrm{wt} \%$ of graphite were milled together under an Ar atmosphere. XRD data were collected to demonstrate the crystal structure and phase composition in the original $\mathrm{Sn}$ powders and Sn-C composite (Fig. 1). Diffraction patterns indicate that both samples are consistent with the tetragonal phase of Sn (JCPDS no. 04-004-7744). No distinguishable peaks of any other phases or impurities were detected, indicating that 


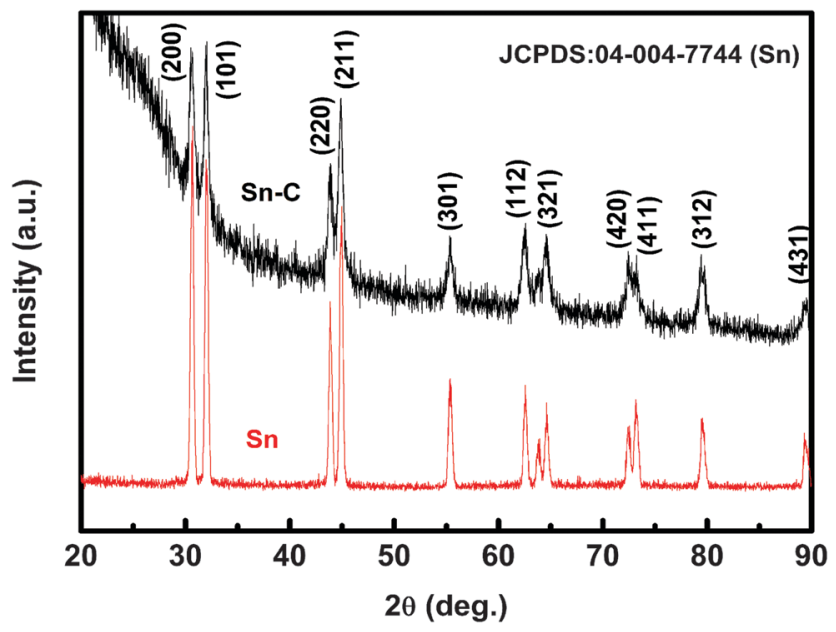

Fig. 1 X-ray diffraction patterns of commercial Sn powder and the Sn-C composite sample.

a Sn-C composite with the reasonably high purity Sn component can be obtained after ball milling. Additionally, the diffraction peaks of the Sn-C sample have a low intensity with respect to the noise level and are broadened, highlighting a small crystallite size of Sn. The (002) graphitic peak at around $26^{\circ}$ is no longer observed clearly, indicating that the graphitic structure in the carbon component is substantially lost after ball milling. The high background at lower double angles (up to $33^{\circ}$ ) originates from a broad peak of Kapton tape used to protect the sample from reactivity with air during the XRD measurement. To double check the composition of the Sn-C sample, energy-dispersive X-ray spectroscopy (EDS) and thermogravimetric analysis (TGA) were carried out (Fig. S1 and S2, ESI $\dagger$ ). EDS examination estimates the presence of $62.6 \mathrm{wt} \% \mathrm{Sn}, 29.3 \mathrm{wt} \%$ carbon, $7.8 \mathrm{wt} \% \mathrm{O}$, and $0.4 \mathrm{wt} \% \mathrm{Fe}$ in the composite. The oxygen contamination originates from the exposure of the sample to air during analysis (most of the electrode preparation was carried out in the glove box, and we believe that the oxygen content in the electrodes is smaller), while the iron contamination is from ball milling media (balls and the milling container). The composition of $65 \mathrm{wt} \% \mathrm{Sn}$ and $35 \mathrm{wt} \%$ carbon was estimated from the TGA data.

To obtain visual information about the structure of the Sn-C composite, TEM analysis was carried out (Fig. 2). A bright-field TEM image of the sample is presented in Fig. $2 \mathrm{a}$ and shows that the sample consists of aggregates of small particles created by ball milling. The compositional distribution is examined by means of energy-filtered TEM. Fig. 2b shows an overlay of energy-filtered elemental maps of carbon (yellow) and Sn (blue), indicating that nanoparticles of $\mathrm{Sn}$ are distributed in the carbon component. Similar $\mathrm{P}-\mathrm{C}$ and $\mathrm{Sb}-\mathrm{C}$ composites have been previously produced by our group using the same ball milling method. ${ }^{22,23}$ A selected area electron diffraction (SAED) pattern is also depicted in Fig. 2c. The SAED pattern is a ring pattern that can be indexed to the tetragonal phase of $\mathrm{Sn}$. These results are consistent with the data in the XRD pattern (Fig. 1). The sample was sensitive to the electron beam, and extreme care was taken not to alter the structure during TEM observation (more information in Fig. S3, ESI $\dagger$ ).

Fig. 3a-c shows the results of the galvanostatic dischargecharge measurements of the electrodes performed at a current rate of $25 \mathrm{~mA} \mathrm{~g}^{-1}$ in the potential range of $2.00-0.01 \mathrm{~V} v s . \mathrm{K} / \mathrm{K}^{+}$ at room temperature. $0.75 \mathrm{M} \mathrm{KPF}_{6}$ in a mixture of ethylene carbonate and diethyl carbonate is used as an electrolyte. It is observed that the $\mathrm{Sn}-\mathrm{C}$ electrode is reactive towards potassium and capable of delivering reversible capacities of $150-170 \mathrm{~mA} \mathrm{~h}^{-1}$ in the course of cycling (the capacities from the charge of the half-cell are shown in Fig. 3a). The initial reversible capacity increases until the eighth cycle and subsequently decreases to about $110 \mathrm{~mA} \mathrm{~h} \mathrm{~g}^{-1}$ after 30 cycles. It is important to consider the contribution to the capacity from the carbon component in the composite because it may be electrochemically active as well. With this in mind, we have also measured the capacity of carbon material produced by milling of pure graphite under similar conditions, and the cyclic behaviour is also plotted in Fig. 3a. It can be seen that the estimated capacity of milled carbon is at a slightly lower level than that of the composite. It is, therefore, reasonable to expect that the Sn component in the electrode has a capacity of $150-190 \mathrm{~mA} \mathrm{~h} \mathrm{~g}{ }^{-1}$. In contrast, very limited capacity is observed in the electrode prepared from coarse pure $\mathrm{Sn}$, indicating that issues with limited capacity and compromised cycling stability for "bulk" Sn electrodes known in lithium and sodium cells ${ }^{19,24}$ are present in potassium cells as well. The Coulombic efficiencies of the electrodes made with the $\mathrm{Sn}-\mathrm{C}$ composite and ball milled carbon are presented in Fig. $3 \mathrm{~b}$. The initial efficiency in the first cycle is around $50 \%$, larger than that of the electrode prepared using ball milled graphite, and monotonously increases to above $80 \%$ after 15 cycles. Importantly, no electrolyte additives typical for sodium cells (e.g., fluoroethylene carbonate (FEC) or vinylene carbonate (VC)) are used in our experiments, and the Coulombic efficiency data may be far from being optimised at this point.

The charge-discharge curves of the $\mathrm{Sn}-\mathrm{C}$ electrode in the first, second, 10th and 15th cycles are shown in Fig. 3c. The discharge-charge processes display characteristic features related to potassium alloying-dealloying reaction, predominantly, with some contribution from potassium insertion into carbon. During the first discharge-charge, an irreversible capacity loss of $148 \mathrm{~mA} \mathrm{~h} \mathrm{~g}^{-1}$ (the first discharge and charge capacities are 288 and $140 \mathrm{~mA} \mathrm{~h}^{-1}$ ) is recorded which is a common feature in battery anodes generally attributed to the formation of a solid electrolyte interface (SEI) layer on the surface of the electrodes. The discharge-charge potential profiles are consistent with the results of cyclic voltammetry (CV), as shown in Fig. 3d. The reduction process (cathodic scan) results in a feature located at 0.9 and $0.01-0.17 \mathrm{~V} v$ s. $\mathrm{K} / \mathrm{K}^{+}$. In the oxidation process (anodic scan), a pair of de-alloying peaks at $0.7,0.83$ and 1.05 and $1.18 \mathrm{~V}$ $v s . \mathrm{K} / \mathrm{K}^{+}$is clearly visualised, which are well matched with miniplateaus in the charge potential profiles. A CV for the pure Sn electrode is also shown in Fig. S4, ESI. $\dagger$ Similar features between 0.7 and $1 \mathrm{~V} v s$. $\mathrm{K} / \mathrm{K}^{+}$are visible in the $\mathrm{CV}$ pattern of this electrode and indicate that the observed electrochemical signatures are specific to the process in the Sn component. 


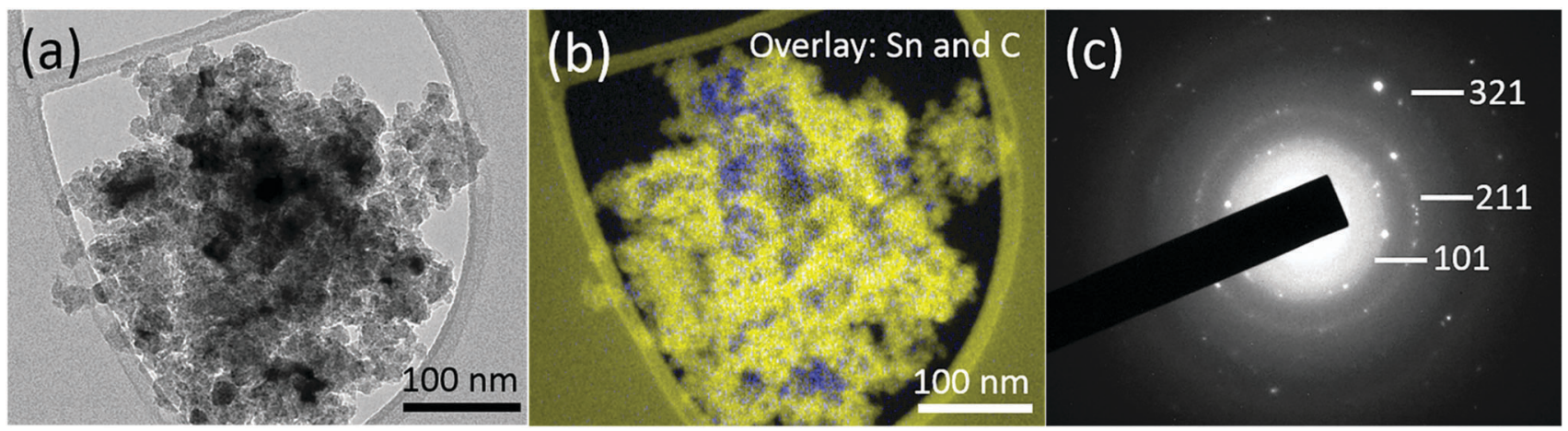

Fig. 2 TEM characterisation: (a) an elastic bright-field image; (b) an overlay of energy-filtered elemental maps of carbon and Sn (colour scheme: C, yellow; Sn, blue); and (c) a SAED pattern of the sample, confirming the tetragonal Sn phase in the sample.
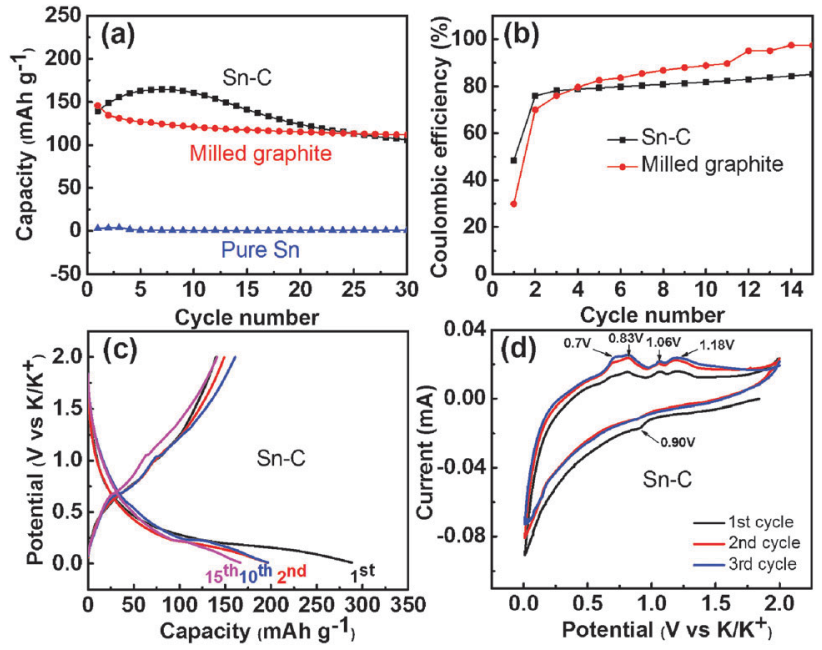

Fig. 3 Electrochemical performance of the electrodes in potassium half-cells: (a) cycling performance at a current rate of $25 \mathrm{~mA} \mathrm{~g}^{-1}$ within $2.00-0.01 \mathrm{~V}$ vs. $\mathrm{K} / \mathrm{K}^{+}$(reversible capacity is shown); (b) the corresponding Coulombic efficiency; (c) galvanostatic discharge-charge potential profiles for the selected cycles; and (d) cyclic voltammograms recorded at a scan rate of $0.05 \mathrm{mV} \mathrm{s}^{-1}$.

The results suggest that, similar to lithium and sodium cells, alloying in the Sn component occurs for potassium, and $\mathrm{K}_{x} \mathrm{Sn}_{y}$ phases form upon the discharge of half-cells. According to the binary phase diagram, a range of phases such as $\mathrm{K}_{2} \mathrm{Sn}$, $\mathrm{KSn}, \mathrm{K}_{2} \mathrm{Sn}_{3}, \mathrm{~K}_{2} \mathrm{Sn}_{5}, \mathrm{KSn}_{2}$ and $\mathrm{K}_{4} \mathrm{Sn}_{23}$ are possible in the potassiumtin system. ${ }^{25}$ In an attempt to shed light on the storage mechanism, XRD analysis was performed on the electrodes after cycling and the XRD patterns are displayed in Fig. 4. In order to identify phases, we attempted to use standard JCPDS diffraction cards available for the potassium-tin alloys. Due to the scarcity of the available diffraction data for these phases, an atomic species swapping method was also attempted. JCPDS cards of known lithium-tin and sodium-tin alloys were looked up, and an assumption was made that analogous potassium alloys may also exist, exhibiting similar (although with, possibly, slightly altered positions) diffraction peaks.

The XRD patterns of the discharge and charge products obtained in the first cycle are shown in Fig. 4 . It can be seen that,

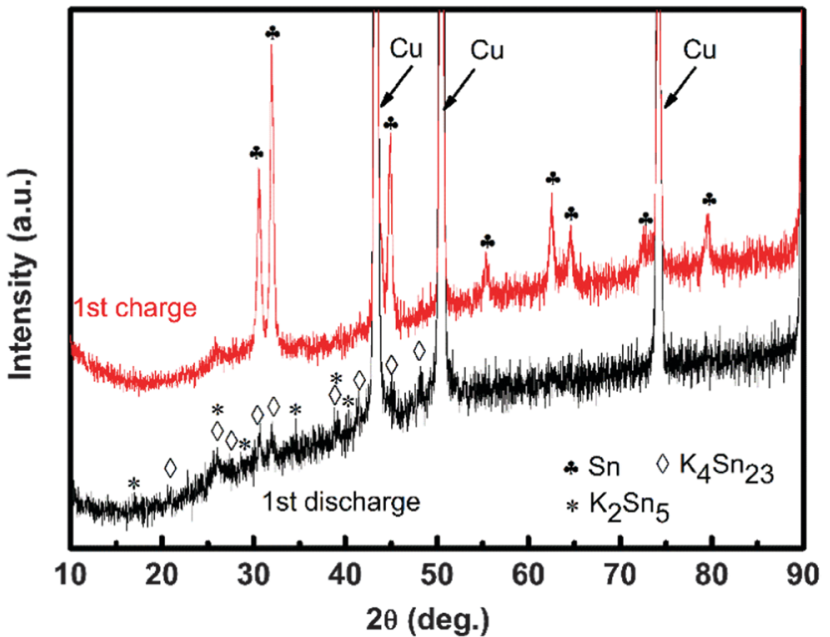

Fig. 4 XRD patterns of $\mathrm{Sn}-\mathrm{C}$ electrodes after the first discharge and the first charge in a potassium half-cell.

after the first discharge to $0.01 \mathrm{~V} v s$. $\mathrm{K} / \mathrm{K}^{+}$, the XRD peaks of $\mathrm{Sn}$ (JCPDS no. 04-004-7744) substantially disappear or at least greatly diminish. The pattern demonstrates a number of diffraction peaks, indicating that not just one phase but a few are visible in the pattern. It is not possible to match these peaks convincingly and our current interpretation of the diffraction pattern is inconclusive. Some of the peaks could originate from Sn (JCPDS no. 04-004-7744), $\mathrm{K}_{2} \mathrm{Sn}_{5}$ (a phase analogous to a known lithium-tin alloy), and $\mathrm{K}_{4} \mathrm{Sn}_{23}$ (JCPDS no. 04-004-8647). After the first charge of the cell back to $2.0 \mathrm{~V} v s$. $\mathrm{K} / \mathrm{K}^{+}$, the XRD pattern confirms the existence of the $\mathrm{Sn}$ phase, indicating a de-alloying process.

A useful exercise is to compare the electrochemical behaviour of this Sn-C composite with potassium and its behaviour in lithium and sodium cells. The discharge-charge curves of lithium and sodium half-cells recorded at the same slow current of $25 \mathrm{~mA} \mathrm{~g}^{-1}$ are shown in Fig. S5 (ESI $\dagger$ ). It can be observed that a reversible capacity of $800 \mathrm{~mA} \mathrm{~h} \mathrm{~g}^{-1}$ is measured in the lithium cell for the composite. Taking into account that the carbon component of the composite is also electrochemically active and assuming that its capacity is limited by the theoretical capacity 
of graphite (372 $\left.\mathrm{mA} \mathrm{h} \mathrm{g}^{-1}\right)$, we can expect that the formation of the $\mathrm{Li}_{4.4} \mathrm{Sn}$ alloy occurs in the $\mathrm{Sn}$ component in the lithium cells, delivering a capacity close to the theoretical value (991 $\mathrm{mA} \mathrm{h}^{-117}$ ) for the Sn component. At the same time, a capacity of only about $350 \mathrm{~mA} \mathrm{~h} \mathrm{~g}^{-1}$ is measured for the $\mathrm{Sn}-\mathrm{C}$ composite in the sodium half-cell. Taking into account that the theoretical capacity of Sn with sodium is $845 \mathrm{~mA} \mathrm{~h} \mathrm{~g}{ }^{-116}$ and assuming that the carbon component is not electrochemically active, the expected capacity in the $\mathrm{Sn}-\mathrm{C}$ composite is still $590 \mathrm{~mA} \mathrm{~h} \mathrm{^{-1 }}$, well above the capacity observed in the experiment. In other words, only a partial alloying process occurs in the sodium cell for the Sn-C sample, and the $\mathrm{Na}_{15} \mathrm{Sn}_{4}$ alloy does not form in the $\mathrm{Sn}$ component.

The results obtained from the sodium cells suggest that the theoretical capacity in the potassium cell is probably not achieved as well in the Sn component due to the more sluggish reaction behaviour of Sn with both sodium and potassium. This has an obvious drawback of the Sn component being unable to reach the final potassium-tin alloy phase, from which the theoretical capacity of $\mathrm{Sn}$ in potassium cells could be calculated, in this study. The discharge products observed in Fig. 4 are probably just a mixture of intermediate phases, unable to reveal the mechanism in the cell fully. The positive implication, however, is the promise of improved electrochemical performance in the optimised Sn-based electrodes. Capacities of only 150-170 $\mathrm{mA} \mathrm{h} \mathrm{g}^{-1}$ are measured in this work, but it may be expected that these values can be increased in the future work through the optimisation of binders and electrode architectures and identifying suitable electrolytes/additives for K-ion cells to support more efficient alloying of tin with potassium.

In summary, a $\mathrm{Sn}-\mathrm{C}$ composite material has been prepared by mechanical ball milling of $70 \mathrm{wt} \%$ Sn powder with $30 \mathrm{wt} \%$ graphite. The material consists of Sn nanoparticles dispersed in carbon (no longer graphitic). The electrochemical experiments demonstrate that the material functions as a negative electrode for K-ion batteries within a potential range of $2.00-0.01 \mathrm{~V} v s . \mathrm{K} / \mathrm{K}^{+}$. The reversible capacities of about $150 \mathrm{~mA} \mathrm{~h}^{-1}$ can be measured. It has been shown through XRD analysis that crystalline phases form upon the discharge of potassium half-cells and decrease in the intensity upon charge, indicating that an alloying process occurs in the Sn component of the electrode. The obtained results broaden the range of materials potentially suitable for the anodes of K-ion batteries, and suggest that further studies of the materials that alloy electrochemically with potassium are worthwhile.
Financial support from an Australian Postgraduate Award (APA) is acknowledged. The work was carried out with the support of the Deakin Advanced Characterisation Facility. The authors thank Mr Robert Lovett for manufacturing tools for preparing potassium reference electrodes and Dr Andrew Sullivan for his assistance in the composition analysis by EDS. Timcal Ltd. is acknowledged for providing a sample of Super $\mathrm{P} \mathrm{Li}^{\mathrm{TM}}$ carbon black.

\section{Notes and references}

1 D. Larcher and J. M. Tarascon, Nat. Chem., 2015, 7, 19.

2 T. Nagaura and K. Tozawa, Progress in Batteries and Solar Cells, JEC Press Inc., Brunswick, OH, 1990, vol. 9, p. 209.

3 M. D. Slater, D. Kim, E. Lee and C. S. Johnson, Adv. Funct. Mater., 2013, 23, 947.

4 N. Yabuuchi, K. Kubota, M. Dahbi and S. Komaba, Chem. Rev., 2014, 114, 11636.

5 S. Komaba, T. Hasegawa, M. Dahbi and K. Kubota, Electrochem. Commun., 2015, 60, 172.

6 D. R. Lide, CRC Handbook of Chemistry and Physics: Special Student Edition, 77th edn, 1996.

7 A. Eftekhari, J. Power Sources, 2004, 126, 221.

8 C. D. Wessells, S. V. Peddada, R. A. Huggins and Y. Cui, Nano Lett., 2011, 11, 5421.

9 N. Recham, G. Rousse, M. T. Sougrati, J. N. Chotard, C. Frayret, S. Mariyappan, B. C. Melot, J. C. Jumas and J. M. Tarascon, Chem. Mater., 2012, 24, 4363.

10 V. Mathew, S. Kim, J. Kang, J. Gim, J. Song, J. P. Baboo, W. Park, D. Ahn, J. Han and L. Gu, NPG Asia Mater., 2014, 6, 138.

11 Z. Jian, W. Luo and X. Ji, J. Am. Chem. Soc., 2015, 137, 11566.

12 W. Luo, J. Wan, B. Ozdemir, W. Bao, Y. Chen, J. Dai, H. Lin, Y. Xu, F. Gu, V. Barone and L. Hu, Nano Lett., 2015, 15, 7671.

13 Z. Jian, Z. Xing, C. Bommier, Z. Li and X. Ji, Adv. Energy Mater., 2016, 6, 1501874 .

14 M. M. Doeff, Y. P. Ma, S. J. Visco and L. C. Dejonghe, J. Electrochem. Soc., 1993, 140, L169.

15 P. Ge and M. Fouletier, Solid State Ionics, 1988, 28, 1172.

16 C. Bommier and X. Ji, Isr. J. Chem., 2015, 55, 486.

17 M. N. Obrovac and V. L. Chevrier, Chem. Rev., 2014, 114, 11444.

18 W. D. McCulloch, X. Ren, M. Yu, Z. Huang and Y. Wu, ACS Appl. Mater. Interfaces, 2015, 7, 26158.

19 J. W. Park, J. Y. Eom and H. S. Kwon, Electrochem. Commun., 2009, 11, 596.

20 Z. Li, J. Ding and D. Mitlin, Acc. Chem. Res., 2015, 48, 1657.

21 Y. Xu, Q. Liu, Y. Zhu, Y. Liu, A. Langrock, M. R. Zachariah and C. Wang, Nano Lett., 2013, 13, 470.

22 T. Ramireddy, T. Xing, M. M. Rahman, Y. Chen, Q. Dutercq, D. Gunzelmann and A. M. Glushenkov, J. Mater. Chem. A, 2015, 3,5572 .

23 T. Ramireddy, M. M. Rahman, T. Xing, Y. Chen and A. M. Glushenkov, J. Mater. Chem. A, 2014, 2, 4282.

24 Y. M. Lin, P. R. Abel, A. Gupta, J. B. Goodenough, A. Heller and C. B. Mullins, ACS Appl. Mater. Interfaces, 2013, 5, 8273.

25 J. Sangster and C. W. Bale, J. Phase Equilib., 1998, 19, 67. 